\title{
An evaluation of methods available for quantifying extreme beach erosion
}

\author{
Douglas Pender • David P. Callaghan • \\ Harshinie Karunarathna
}

Received: 2 June 2014 / Accepted: 21 July 2014 / Published online: 3 September 2014

(C) Springer International Publishing AG 2014

\begin{abstract}
To allow for effective and sustainable coastal management and planning it is important to have the tools available to estimate extreme beach erosion levels. This paper, therefore, presents an evaluation of methods available for quantifying extreme beach erosion. Previous common practice is the use of a single benchmark ( 1 in $N$ year) event to estimate the corresponding extreme erosion level. The limitations of this approach led to the development of more sophisticated temporal simulation frameworks providing robust statistical quantification of extreme beach erosion. These developments have resulted in a number of follow on studies to progress the methodology in line with a range of coastal morphodynamic modelling approaches. The discussion presented here, begins with basic empirical techniques and progresses up to those conducted using the most up-todate morphodynamic models. Each methodology is applied to Narrabeen Beach, NSW, Australia, to compare and assess their suitability. The development of these methodologies is a relatively new topic, meaning that there is much scope for further progression. Although the use of state-of-the-art morphodynamic models is shown to give a good representation of erosion volumes, their impracticalities seem to outweigh
\end{abstract}

\footnotetext{
D. Pender $(\varangle)$

Institute for Infrastructure and Environment,

Heriot-Watt University, Edinburgh EH14 4AS, UK

e-mail: d.pender@hw.ac.uk

D. P. Callaghan

School of Engineering, University of Queensland,

Brisbane 4072, Australia

e-mail: dave.callaghan@uq.edu.au

H. Karunarathna

College of Engineering,

Swansea University, Singleton Park, Swansea SA2 8PP, UK

e-mail: h.u.karunarathna@swansea.ac.uk
}

the benefits. Incorporation of more realistic estimations of the storm and wave climate and the requirement for global evaluation are identified as central to further development.

Keywords Beach erosion - Statistical analysis - Morphodynamic modelling $\cdot$ XBeach $\cdot$ Narrabeen Beach

\section{Introduction}

As the global population continues to rise, so does the population that lives within, and relies upon, the coastal regions (Small and Nicholls 2003). In many regions beaches provide natural protection to communities at risk from coastal flooding. This, combined with their socioeconomic importance, means that quantifying the erosion and recession of these systems is of paramount importance for a wide range of ocean and coastal engineering projects. It is, therefore, imperative that coastal engineers and scientists have the appropriate tools and knowledge to understand these systems and ensure that their changes can be appropriately mitigated through engineering applications.

It is now commonly accepted that the changing global climate is mainly responsible for the observed rise in mean sea level over the past decades. With this likely to accelerate, adverse effects on the stability of beaches will result (Church and White 2006). The effects of rising sea levels on beaches have been investigated for a number of years with Bruun (1962), providing one of the first methods for quantifying sea level rise-led beach recession. This methodology has progressed along with advances in coastal morphodynamic modelling techniques and is still actively researched today (Cooper and Pilkey 2004; Dissanayake et al. 2009; Ranasinghe et al. 2011; Reeve and Karunarathna 2009; Stive et al. 2009). 
Fig. 1 Location and orientation of Narrabeen Beach within New South Wales. Modified after Harley et al. (2011b)

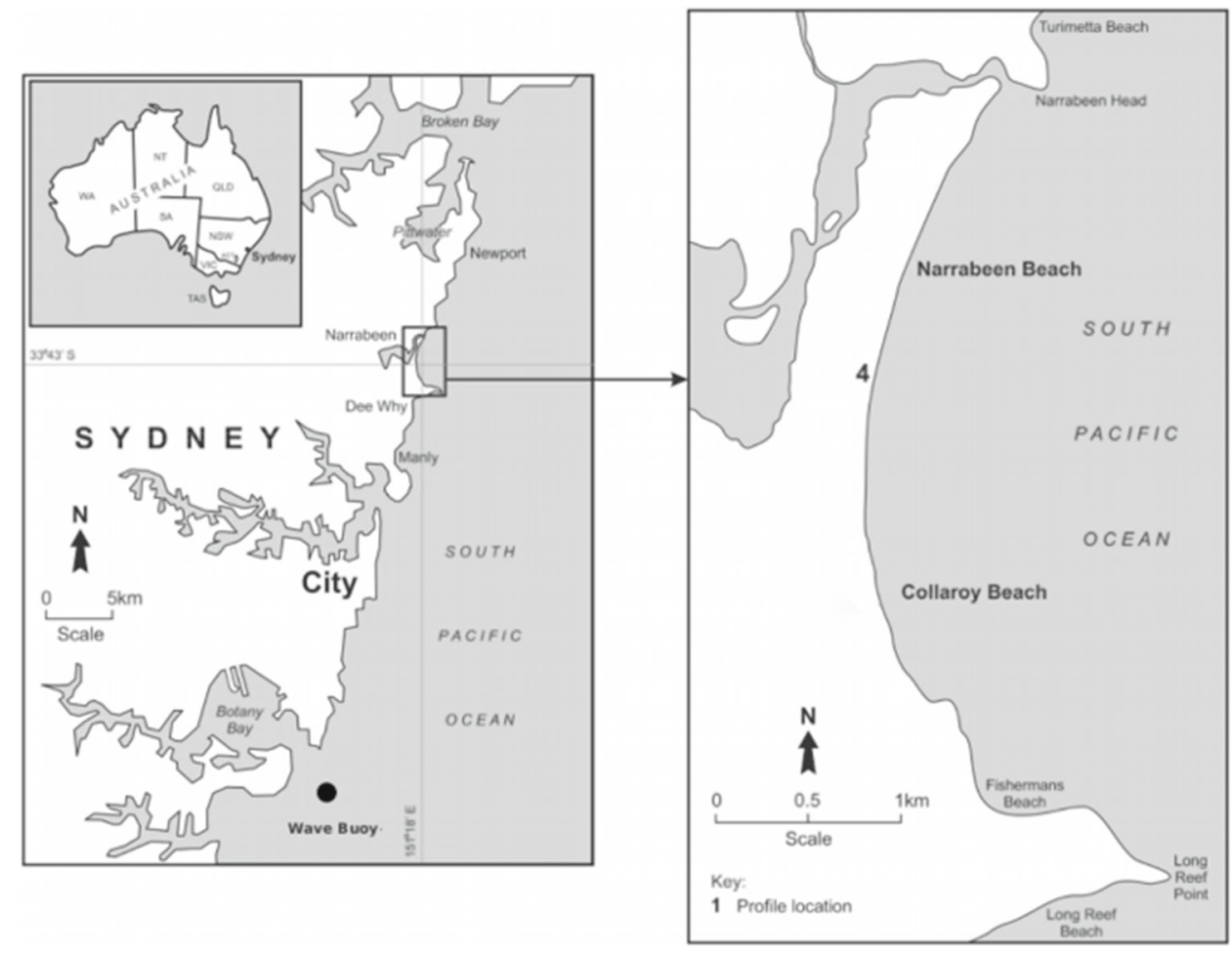

Historically, beach erosion from extreme events was estimated by applying a benchmark ( 1 in $N$ year) event. For multivariate coastal systems, the use of such a method is entirely inappropriate as demonstrated by Hawkes et al. (2002), who showed that the return period of the erosion is not necessarily equal to that of the forcing conditions (i.e. a 1:100 year wave height may not produce 1:100 year erosion). The realisation of the importance of including multivariate forcing conditions has resulted in the recent development of estimation techniques within coastal engineering research (Ranasinghe et al. 2011; Pender and Karunarathna 2013; Callaghan et al. 2008). These techniques have progressed along with current advances in morphodynamic modelling and provide considerably more comprehensive and robust estimates of beach erosion than can be achieved using a benchmark event.

This paper aims to collate and compare all of the current methods available for quantifying extreme beach erosion and provide a detailed analysis of each method. The analysis begins with the simplest data-driven estimations and expands up to the use of the latest morphodynamic modelling software within predictive frameworks. This will provide a comprehensive understanding of the methodologies developed for estimating extreme beach erosion by highlighting the benefits/shortcomings of each.

To progress these types of modelling approaches for use in practical situations a number of key developments are required. These developments, and the requirement for global validation and applicability, are discussed in detail.

\section{Field site}

\subsection{Narrabeen Beach}

Narrabeen Beach is a 3.6-km long embayed beach located approximately $20 \mathrm{~km}$ north of Sydney, NSW, Australia (Fig. 1). The beach is subjected to a highly variable, moderate- to high-energy wave climate, driven by a number of cyclonic sources, with storms reaching the beach throughout the year (Short and Trenaman 1992; Short 2006). It experiences semi diurnal, micro-tidal conditions with a mean spring tidal range of $1.25 \mathrm{~m}$ (Short 1984).

The beach itself predominantly exhibits the shape of an intermediate state, but has been shown to frequently change between a number of different states (Wright and Short 1984). The beach sediments are quartz and carbonate sands with median diameter $\left(D_{50}\right)$ ranging from 0.25 to $0.50 \mathrm{~mm}$ (Wright and Short 1984). During the last few decades the morphodynamic variability of the beach has been regularly and extensively monitored using profile surveys at five locations, at approximately monthly intervals, along the beach (Short and Trembanis 2004). Due to the orientation of the beach it suffers from El Niño/La Niña-driven beach rotation (Harley et al. 2011a; Ranasinghe et al. 2004) with erosion and accretion occurring at the northern and southern ends in line with El Niño/La Niña. It was shown that profile 4 (Fig. 1) is the measured profile least influenced by these effects and acts a fulcrum during rotation (Ranasinghe et al. 2004). 


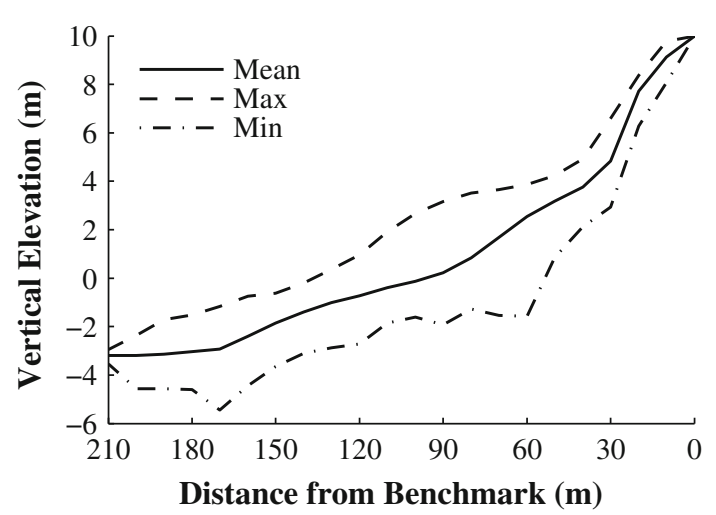

Fig. 2 Profile envelope for profile 4 from beach surveys between 1976 and 2006. The benchmark was kept consistent at the crest of the dune and $\mathrm{MSL}=0 \mathrm{~m}$

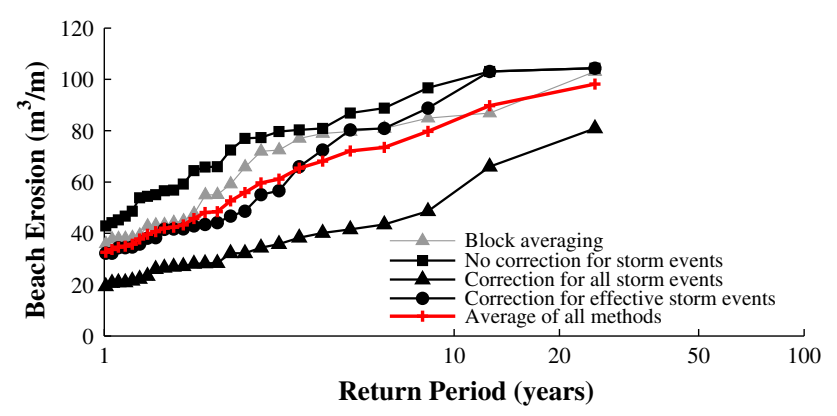

Fig. 3 Empirical erosion return levels at Narrabeen Beach determined from the methods of Callaghan et al. (2008), combined with an average of their approaches

Therefore, beach surveys of profile 4 are considered as the most suitable for validating beach erosion modelling frameworks. Figure 2 shows the envelope of profile 4 for the measurement period between 1976 and 2006. This highlights the high degree of variability in the beach due to frequent occurrence of high-energy storm events in the region.

At Narrabeen Beach, it has become common practice to determine erosion above the $2 \mathrm{~m}$ beach contour (Ranasinghe et al. 2011; Pender and Karunarathna 2013; Callaghan et al. 2008; Hoffman and Hibbert 1987) as this is above regular tidal limits and therefore only affected by high wave events. The additional analyses conducted in this study define erosion in the same way to allow for comparison of methods. To assess the success of the individual methodologies, the results are compared with the measured levels of erosion at profile 4 .

Callaghan et al. (2008) calculated measured erosion return levels at profile 4 of Narrabeen Beach using four techniques. These are: block averaging; consecutive volumes with no correction; consecutive volume corrected for the number of storms; and consecutive volumes corrected for the number of effective storms. The results are given in Fig. 3, with the mean of all techniques used to provide a consistent comparison to the methodologies discussed in this paper. A summary of these techniques is provided below with more details given in Callaghan et al. (2008). (a) Block-averaging Determine the erosion levels from the measured profiles in 1.5 month blocks. This ensures that every block has at least 1 profile measurement.

(b) Consecutive volumes with no correction Determine the change in beach volume between consecutive profiles.

(c) Consecutive volumes corrected for the number of storms Same as (a) but with the erosion volume divided by the number of events between the profile measurements.

(d) Consecutive volumes corrected for the effective number of storms Same as (a) but with the erosion volume divided by the number of effective events between the profile measurements. The number of effective events were defined by a rule-of-thumb approach that suggests; if there were significantly large events, count only these events; otherwise remove small events compared to the remaining events; and if unclear, count all events.

\subsection{Wave data}

Wave data collected between 1981 and 2005, using a waverider buoy deployed offshore of Botany Bay (Fig. 1) at a water depth of $85 \mathrm{~m}$, were used in this study. During the recording period, the overall wave climate was highly variable. The mean significant wave height $\left(H_{\mathrm{s}}\right)$ and significant wave period $\left(T_{\mathrm{S}}\right)$ were approximately $1.5 \mathrm{~m}$ and $10 \mathrm{~s}$ respectively; with the 95 and $99 \%$ exceedance limits of $H_{\mathrm{S}}$ being 3.17 and $4.30 \mathrm{~m}$, respectively. Figure 4 shows the distribution of $H_{\mathrm{S}}$ and $T_{\mathrm{S}}$ for the data set in question. From 1992 to present, a directional Waverider buoy has also been deployed offshore of Long Reef point (Fig. 1). More information on the NSW wave climate can be found in Short and Trenaman (1992), Lord and Kulmar (2000), Kulmar et al. (2005) and Harley et al. (2010).

\subsection{Storm events}

Based on the analysis of the incident wave climate and erosion in the Narrabeen region, a correlation between large wave heights and erosion was evident (Harley et al. 2009). To determine the storm wave climate at Narrabeen, Kulmar

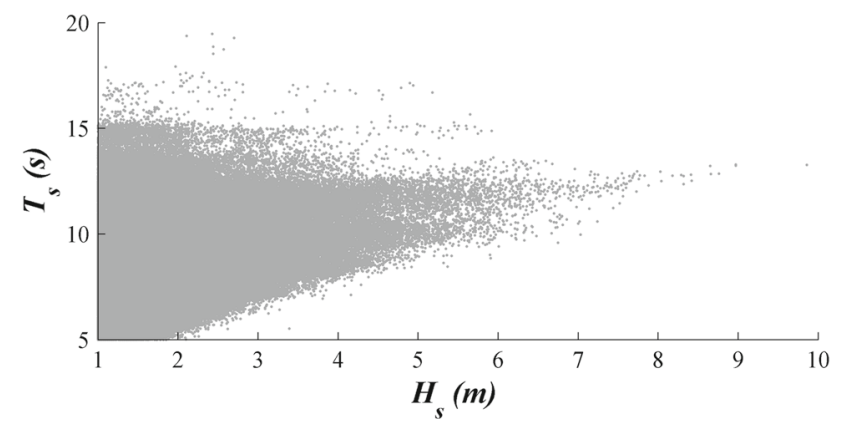

Fig. 4 Distribution of recorded $T_{\mathrm{s}}$ vs. $H_{\mathrm{s}}$ from 1981-2005 
et al. (2005) extracted storm conditions from the measured wave climate, taking a $3.0 \mathrm{~m}$ wave height as the threshold condition that defines a storm wave. The extraction of storm time series allows determination of long-term storm statistics and hence derivation of synthetic storm climates that are used in the modelling procedures described throughout this paper.

\section{Extreme value estimation from empirical data}

The estimation of extreme values (for any variable) from empirical data is commonly implemented using two techniques. These are the Annual Maxima (AM) and the Peaks Over Threshold (POT) techniques. This section applies both techniques to the measured erosion volumes at profile 4 of Narrabeen Beach in order to estimate extreme beach erosion levels. These are implemented using the measured beach profiles from 1981 to 2005 (Short and Trembanis 2004) and the corresponding erosion levels derived in the previous section. Both AM and POT methods apply the following procedure: (a) Determine empirical erosion from measured beach profiles. (b) Fit an extreme value distribution to the data. (c) Invert extreme value distribution to determine return periods. (d) Plot return levels $v s$. return periods and read off desired extreme values.

\subsection{Annual Maxima technique}

The AM technique for estimating extremes is the simplest approach available, with the maximum annual erosion determined from the measured data used for model fitting. It is common knowledge that the main limitations in this method lie with the possibility that non-extreme values may be included and the occurrence of multiple extreme values will be omitted. The omission of extreme values is almost expected in AM modelling but the inclusion of non-extremes is also a cause for concern, especially when deriving erosion volumes at lower return periods. Also, it is unlikely that most surveys at profile 4 capture the exact storm erosion as a result of their timing. Due to the nature of the measurement programme, where focus was given to capturing the general morphodynamic variability of the beach, the surveys have been conducted at regular monthly intervals rather than capturing storm impacts. As a result, it is likely that some beach erosion volumes obtained from the AM analysis of the empirical erosion are not true extreme values.

For the estimation of extremes, there are a number of distributions that can be fitted to the data (e.g. Gumbel, Fréchet or Weibull distributions). However, for the purposes of this study, the Generalised Extreme Value (GEV) distribution (Eq. 1) was fitted to the empirical erosion and used to estimate the extreme levels. The GEV was chosen as it is a combina- tion of the three previously mentioned distribution families, with the shape parameter $(\xi)$ governing the tail behaviour of the distribution where, $\xi \rightarrow 0, \xi>0$ and $\xi<0$ represents the Gumbel, Fréchet and Weibull distributions, respectively.

$\operatorname{Pr}\{X \leq x\}= \begin{cases}\exp \left\{-\left[1+\xi\left(\frac{z-\mu}{\sigma}\right)\right]^{-1 / \xi}\right\} & \xi \neq 0 \\ \exp \left\{\exp \left[-\left(\frac{z-\mu}{\sigma}\right)\right]\right\} & \xi=0\end{cases}$

where $\mu$ is the location parameter; $\sigma$ is the scale parameter; and $\xi$ is the shape parameter. The AM values of beach erosion are provided in Fig. 5a. It can be seen that there is a considerable difference between the maximum $\left(104.8 \mathrm{~m}^{3} / \mathrm{m}\right)$ and the minimum $\left(18.7 \mathrm{~m}^{3} / \mathrm{m}\right)$ erosion volumes, while the mean $\left(60.1 \mathrm{~m}^{3} / \mathrm{m}\right)$ and standard deviation $\left(23.5 \mathrm{~m}^{3} / \mathrm{m}\right)$ emphasises the variability in the data. This reinforces the concerns raised previously on the inclusion of non-extreme values in the distribution fitting. Nonetheless, the GEV distribution was fitted to the measured AM data using maximum likelihood estimation (MLE), which resulted in parameter estimates of $\mu=$ $52.4 \mathrm{~m}^{3} / \mathrm{m}, \sigma=22.2 \mathrm{~m}^{3} / \mathrm{m}$ and $\xi=-0.256$. Upon the estimation of these parameters the return levels $\left(z_{p}\right)$ were determined for a range of return periods (RP) by inverting Eq. (1) to give Eq. (2). The estimation of return levels using the GEV fitted to AM data is shown in Fig. 5b.

$z_{p}=\mu-\frac{\sigma}{\xi}\left[1-\{-\log (1-p)\}^{-\xi}\right]$

where: $\operatorname{Pr}\{X \leq x\}=(1-p)$ and the $\mathrm{RP}$ is $1 / p$.

\subsection{Peaks Over Threshold technique}

The POT technique is considered to provide a more complete description of the historical extreme levels (Coles 2001) as it is not confined to only one event per year. This means that it allows for a more balanced selection and inclusion of all data considered to be extreme. The implementation of the POT approach requires the selection of a suitable threshold to distinguish between ' normal' and 'extreme' values. This selection is down to the modeller and depends very much on the data being modelled. In many cases, threshold selection is based on the $95 \%$ exceedance value. Although this may be suitable for a number of applications, the suitability primarily depends on the use of the data. It is, therefore, recommended that the suitability of a number of thresholds should be considered prior to a final decision. Guidelines for threshold selection are given in detail in Coles (2001) and Thompson et al. (2009).

POT modelling is commonly implemented using the Generalised Pareto distribution (GP) (Coles 2001) provided in Eq. (3).

$$
\operatorname{Pr}\{X \leq x\}=\left\{\begin{array}{l}
1-\zeta_{u}\left[1+\left(\frac{x-u}{\sigma}\right)\right]^{\frac{-1}{\xi}} \text { for } \xi \neq 0 \\
1-\zeta_{u}\left[\exp \left(-\frac{x-u}{\sigma}\right)\right] \text { for } \xi=0
\end{array}\right.
$$


Fig. 5 Annual Maxima erosion levels (a); GEV estimated return levels (b); Peaks Over

Threshold erosion levels (c); and GP estimated return levels (d) (a)

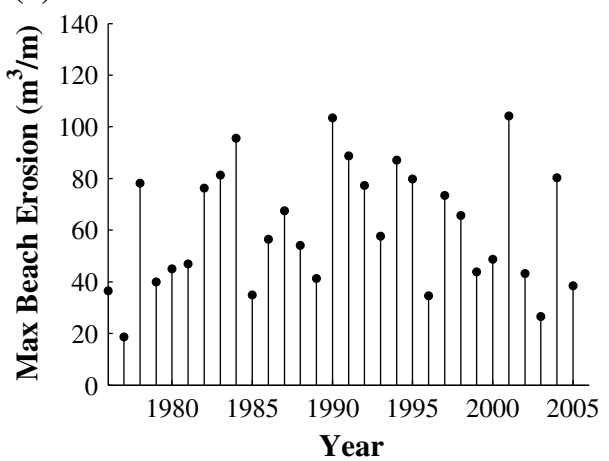

(c)

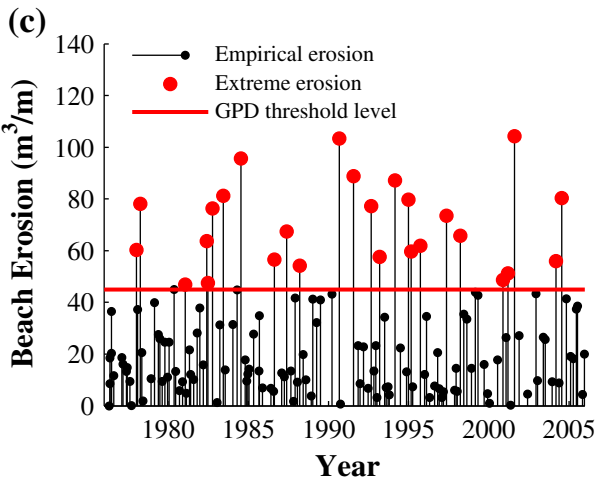

(b)

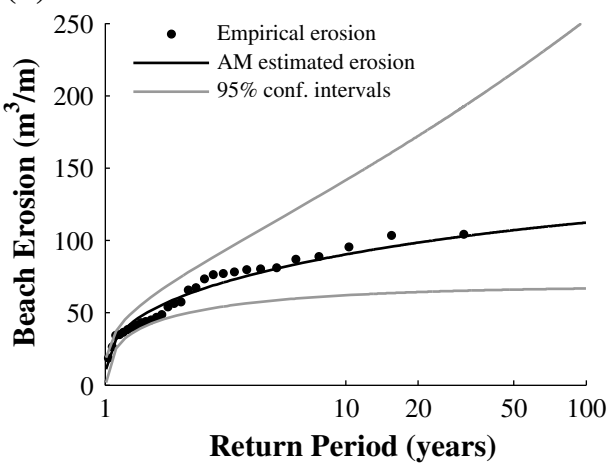

(d)

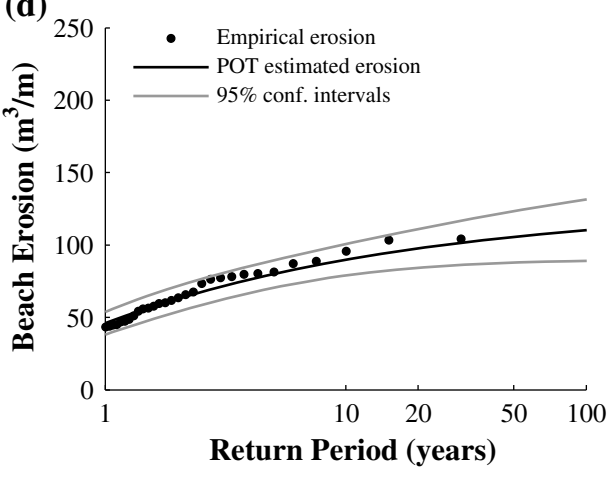

where $u$ is the threshold level; $\sigma$ is the scale parameter; and $\xi$ is the shape parameter; $\zeta_{u}=\operatorname{Pr}\{X>u\}$.

Similar to the GEV, upon estimation of the model parameters, the return levels $\left(z_{\mathrm{p}}\right)$ can be determined by inverting Eq. (3) to give Eq. (4).

$z_{p}=\left\{\begin{array}{l}u+\frac{\sigma}{\xi}\left[\left(m \times \zeta_{u}\right)^{\xi}-1\right] \text { for } \xi \neq 0 \\ u+\sigma \log \left(m \times \zeta_{u}\right) \text { for } \xi=0\end{array}\right.$

where $m$ is the number of events per year $\left(N \times n_{y}\right)$.

Following the procedure explained in Coles (2001), a threshold value of $45 \mathrm{~m}^{3} / \mathrm{m}$ is used for the fitting of the GP to the beach erosion volumes at profile 4 of Narrabeen Beach. Figure $5 \mathrm{c}$ shows the erosion data for fitting the GP using the $45 \mathrm{~m}^{3} / \mathrm{m}$ threshold. Although this threshold level results in less data fitted compared with the AM approach (26 rather than 30 in AM), the data that are fitted can be considered as a better representation of the true extremes. This is highlighted by the mean value of the fitted data set increasing from 60.9 to $70.1 \mathrm{~m}^{3} / \mathrm{m}$, when the POT technique is used. Additionally, the standard deviation decreases to $16.8 \mathrm{~m}^{3} / \mathrm{m}$ (from $23.5 \mathrm{~m}^{3} / \mathrm{m}$ ) showing that the fitted data have a lower variability than the AM values. The GP was then fitted to the data using a MLE approach and converged for: $u$ $=45.0 \mathrm{~m}^{3} / \mathrm{m}, \sigma=46.2 \mathrm{~m}^{3} / \mathrm{m}$ and $\xi=-0.757$. The estimated return levels using these parameters are shown in Fig. $5 d$. A negative estimation of the shape parameter $(\xi)$ indicates that the data best fit a Weibull distribution and that the tail exhibits a finite upper limit. A finite upper limit shows that the estimations correspond with what is physically expected with extreme storm erosion levels, as there is a finite limit to the energy available for the forcing conditions (Callaghan et al. 2013).

From comparison of the return period plots (Fig. 5b, d) the difference attributed to each technique becomes evident. At the lower RPs (1-2 years) the influence of the non-extreme events used in the AM approach show significant underestimation of the return levels compared with those of the POT. However, these differences become negligible as the RP increases, with very little differences observed at the 100 year RP (approx. 2 \%). However, it should be noted that although there is little difference in the estimates at higher RPs, there is considerable difference in the width of the $95 \%$ confidence intervals. This can be attributed to the AM series potentially missing extreme (non-maximum) data, resulting in less confidence in the method than the POT approach.

Although the AM technique is the simplest to apply, care should be taken to ensure that all data considered are extremes. For data sets, such as that of Narrabeen Beach, that may not truly capture extreme levels, a POT approach is considered more appropriate.

It should be noted that these two methods can only be implemented when long-term continuous profile or erosion measurements exist, which are relatively rare. Even if such a location exists, it is then important that the data are representative of storm induced erosion. In the case of Narrabeen 
Beach, although regular profile surveys are available, these were not taken for the specific purpose of capturing storm induced erosion. This may mean that the extreme return levels estimated from the fitted distributions are significantly lower than the true extreme values.

In addition to the requirement of an extensive data set, this method cannot incorporate the effects of potential changes to future wave climate as a result of global climate change. With this becoming an increasingly important factor in the management and engineering of coastal systems such an approach is now outdated. However, should an appropriate data set be available, this quick estimation can still provide a starting point to assess the success and suitability of more advance methods.

\section{Modelling 1 in $N$ year events}

The analysis and design involved in many coastal engineering projects has historically been based around the impact of a 1 in $N$ year extreme event where only a univariate (i.e. wave height) is considered. It has been shown that, storm-induced beach erosion is not only dependent on storm wave height but also on storm duration (Kriebel and Dean 1993). Therefore, a bivariate (wave height and duration) estimation of these events is required to more accurately quantify the erosion induced by extreme events.

For storm events at Narrabeen Beach, Callaghan et al. (2008) produced a bivariate model of peak significant wave height $\left(H_{\mathrm{s}, \max }\right)$ and storm duration $(D)$ by fitting the GP and the logistics model of Tawn (1988), given in Eq. (5).

$$
\begin{aligned}
\operatorname{Pr}\{X \geq x, Y \geq y\}= & 1-e^{-x^{-1}}-e^{-y^{-1}} \\
& +e^{-(x y)^{-1}\left(x^{-\alpha^{-1}}+y^{-\alpha^{-1}}\right)^{\alpha}}
\end{aligned}
$$

where $x$ and $y$ are transformed Fréchet variates and $\alpha$ is the dependency between these.

The models were fitted to the storm event occurrences outlined previously, with the threshold levels of the marginal distributions determined following the procedure of Coles (2001). A full description of the fitting procedure can be found in Callaghan et al. (2008) and Coles (2001).

From these fitted parameters the bivariate return periods $\left(T_{\mathrm{RP}}\right)$; for $N_{\mathrm{Y}}$ events per year can be determined by solving $\operatorname{Pr}\{X \geq x, Y \geq y\}$. Figure 6a shows the bivariate return period plots for $H_{\mathrm{s}, \max }$ and $D$. As the storm model is bivariate there are numerous combinations of $H_{\mathrm{s}, \max }$ and $D$ that give the same return period. Therefore, to provide a comprehensive estimation of the erosion, five storm events at 1, 5, 10, 20, 50 and 100 year return periods (Fig. 6a and Table 1) and 'worst case' (maximum) erosion volume was determined. The five events were chosen to provide a wide
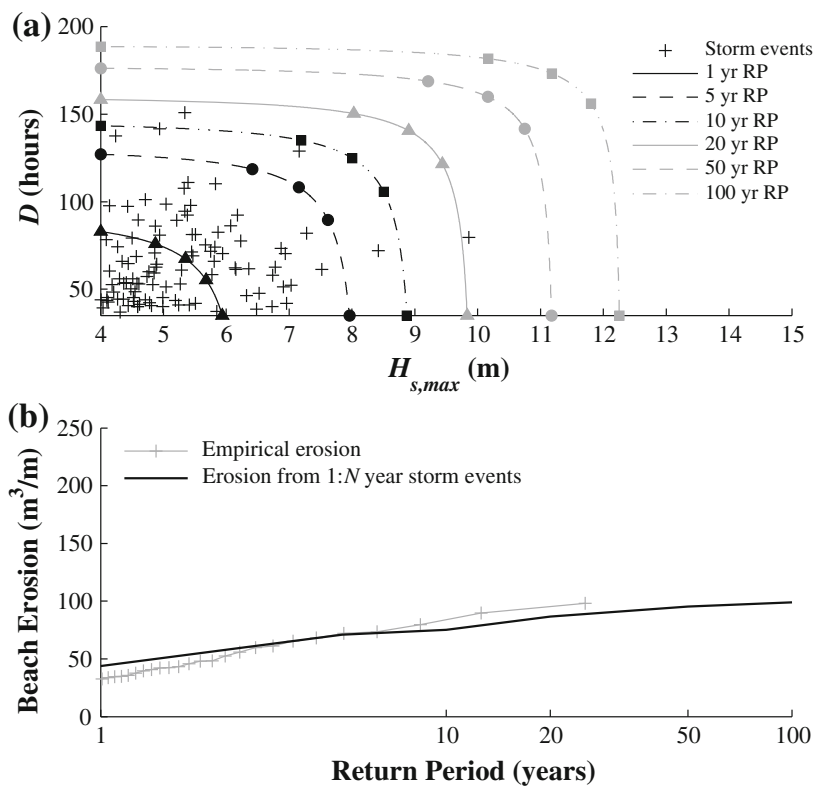

Fig. 6 Bivariate storm event return periods (a); and 1: $N$ year modelled return levels (b)

range of events with the same RP as evident in Fig. 6a. The modelling results are provided in Fig. $6 \mathrm{~b}$.

XBeach (Roelvink et al. 2009, 2010) has become one of the most widely used process-based models for simulating storm impact and dune erosion. As such it has been successfully applied to numerous field sites (Bolle et al. 2010; Lindemer et al. 2010; McCall et al. 2010; De Alegria et al. 2010; Williams et al. 2012). Pender and Karunarathna (2013) calibrated XBeach for simulation of storm erosion at Narrabeen Beach during four storm events, of varying magnitudes, using the wave and profile data discussed previously. The calibration involved systematic testing of a range of model parameters (the Chézy coefficient; the permeability coefficient; and the gradient of wet cells prior to avalanching) that controlled the erosion of the beach. This procedure resulted in a 'good' (0.76) average Brier Skill Score, based on the classification of Van Rijn et al. (2003), across all four events. For the modelling conducted in this study, the same XBeach calibration has been used. The results of the model calibration are shown in Fig. 7 with details of the calibration process and parameter setup given by Pender and Karunarathna (2013).

A first glance at the results presented in Fig. $6 \mathrm{~b}$ indicates a very good correlation between the empirical and modelled return levels. However, we know that the use of a 1:N year event is a limited approach (Hawkes et al. 2002) and it is proposed that this visible correlation is due to inadequacies of the measured profile data (i.e. they do not fully capture erosion from individual events).

Although not presented, the erosion volumes, for all five events, at each RP, show considerable variation. This highlights why the application of a single 1 in $N$ year benchmark 
Fig. 7 XBeach model calibration of Pender and Karunarathna (2013) for modelling storm erosion at Narrabeen Beach. MSL $=0 \mathrm{~m}$ (a)

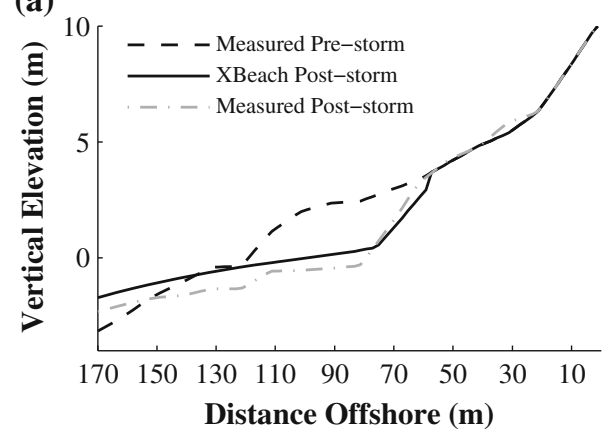

(c)

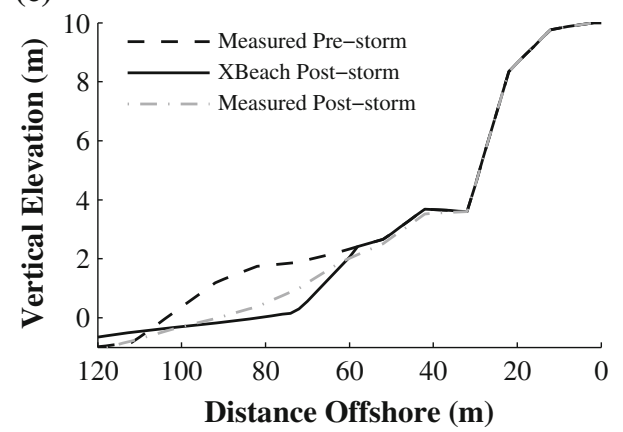

(b)

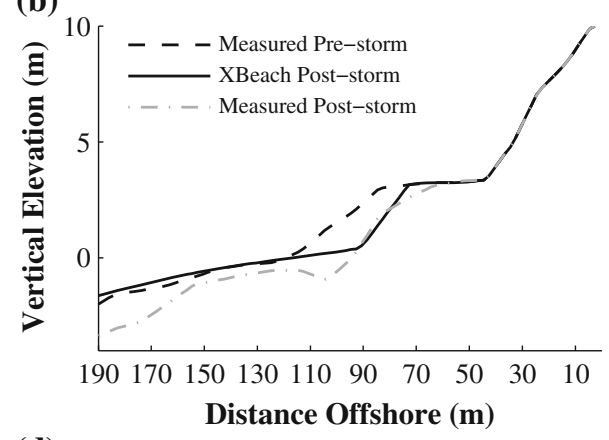

(d)

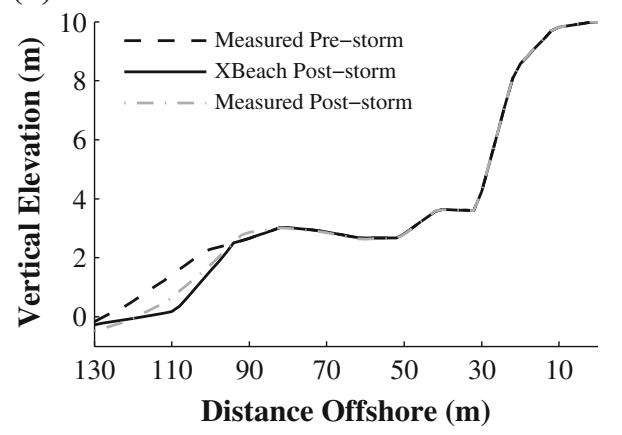

event is not appropriate and demonstrates the requirement for a multivariate RP estimation ( $H_{\mathrm{s}, \max }$ and $D$ as a minimum) and the modelling of a range of extreme events to provide a realistic return level, should a 1: $N$ year event approach be considered.

Also, there is a smaller degree of variability in erosion volumes between RPs than may be expected, with an increase of only $50 \%$ from the 1 to 100 year RP. For an event as extreme as 1 in 100 years, a significantly larger erosion volume may be expected compared with that of an annual RP. The reason for this small variability may be attributed to the rate of erosion being greatest during the initial phase of the storm and then reducing as the eroded profile moves towards an equilibrium state. Therefore, although the events modelled have accounted for event duration in addition to wave height, the simple simulation of 1:N year events is not sufficient for producing realistic extreme erosion levels.

Unlike the estimation of erosion using AM and POT, this method allows the inclusion of projected climate change effects into the forcing conditions. This cannot be achieved using a historical wave record as demonstrated here but, synthetic future wave climates derived from numerical wave prediction models may be used to estimate erosion levels resulting from future wave conditions. A bivariate 1: $N$ year approach is, therefore, more detailed and robust than that of the empirical approach, but it is again not without its limitations. The main one of which is the inability for successive storm events to result in one combined erosive period. Should this occur the second event may essentially pick up from where the first event finished and the resulting erosion be greater than if the events occurred in isolation. This requires a more detailed statistical model of the incident storm climate that allows for the inclusion of storm frequency. A few studies (Callaghan et al. 2009; Splinter et al. 2011; Ferreira and Soares 2000; Karunarathna et al. 2014) have shown that the frequency and grouping of storm events is a controlling mechanism for the observed erosion levels of beaches. This means that incorporating a methodology to account for time and beach recovery between storm events is a key for accurately estimating extreme beach erosion.

\section{Estimation of extreme beach erosion using a synthetic storm climate}

\subsection{Statistical simulation of a synthetic storm climate}

The results and discussion presented in the previous sections have demonstrated the requirement for the progression of the statistical techniques used for estimation of extreme erosion. The most significant contribution to the progression of extreme estimation techniques is that of Callaghan et al. (2008), who developed a statistical procedure that enabled detailed temporal modelling of a storm climate. This approach allows for the generation of a synthetic time series of storm events that can be used as the forcing conditions to estimate beach erosion. This includes an estimation of storm spacing, thus allowing for the recovery/accretion of the beach profile between events and the merging of storms into single erosion events. The model was implemented using the measured storm climate of the Sydney region discussed pre- 
viously in Sect. 2.3. The procedure, therefore, requires data of peak significant wave height $\left(H_{\mathrm{s}, \max }\right)$, duration $(D)$ and spacing $(S)$ of storm events; in addition to the full $H_{\mathrm{s}}$ and $T_{\mathrm{S}}$ of the wave climate. The statistical modelling procedure was additionally used by Ranasinghe et al. (2011) and Pender and Karunarathna (2013), and can be simplified as follows, with a detailed description provided in the references above:

(i) Identify meteorologically independent storm events

(ii) Fit the GP to $H_{\mathrm{s}, \max }$ and $D$

(iii) Fit the dependency (logistics) distribution between $H_{\mathrm{s}, \max }$ and $D$

(iv) Fit the 3-parameter lognormal distribution to pairs of $H_{\mathrm{S}}$ and $T_{\mathrm{S}}$

(v) Fit a non-homogeneous Poisson process to $S$

(vi) Simulate the storm climate using the fitted distributions, including $S$.

\subsection{Full Temporal Simulation approach}

To account for the frequency of storm occurrence, Callaghan et al. (2008) simulated the beach response for an entire synthetic storm time series, including the recovery between events. This model, known as the Full Temporal Simulation (FTS), uses the approach detailed above for generating a storm climate along with the dune erosion model of Kriebel and Dean (1993) as the structural function to determine storm induced beach erosion, and a time-dependent empirical recovery rate between storm events. This was the first attempt at detailed long-term modelling of storm-induced beach erosion.

Due to the simplicity of the structural functions used to determine erosion and recovery, the FTS is very computationally efficient. This resulted in Callaghan et al. (2008) simulating a 50,000 year synthetic storm climate to ensure convergent predictions at the 100 -year return period. The results from this are presented in Fig. 8 and are shown to give good correlation with the empirical erosion volumes determined from measured profiles at profile 4 of Narrabeen Beach.

Comparing the results from the estimation from the 1:N year events (Fig. 6b) the main limitation of that method becomes apparent. At the 100 year RP, the FTS indicates a considerably higher $(\approx 50 \%)$ erosion volume than the simpler method. Although this, again, could possibly be due to the inadequacy of the measured data (i.e. insufficient period to accurately estimate extremes; do not fully capture storm erosion) it is proposed that it is mainly due to the omission of the merging of extreme events, as previously discussed. This comparison provides a valuable indication on why the representation of a full storm climate is an important factor when estimating extreme erosion.
The original structural function used in the FTS model included wave propagation with wave refraction and shoaling based on the bathymetric data. This wave propagation model was updated by Callaghan and Wainwright (2013) to include the non-linear effects of breaking, bottom friction, diffraction, refraction and shoaling, directional spreading and water surface variations. The results from the new model compared with the original FTS model are also shown in Fig. 8. From this it is evident that the more detailed wave propagation model results in a lower estimation of extreme erosion levels and a better fit to the empirical data. For this reason, future discussion of the suitability of the FTS model within this paper is in reference to that of Callaghan and Wainwright (2013).

Although the FTS model is able to simulate continuous beach erosion, the use of an empirical structural function to determine the erosion and recovery of the beach is the main limitation of the model. However, the use of the simplified erosion model of Kriebel and Dean (1993) meant that a simulation of 50,000 years was manageable for Callaghan et al. (2008).

Recently, Callaghan et al. (2013) provided a comparison between the ability of combining three numerical models with the statistical methodology of Callaghan et al. (2008) and the wave propagation method of Callaghan and Wainwright (2013). This assessment included the empirical model of Kriebel and Dean (1993), SBEACH (Larson and Kraus 1989 ) and XBeach with the results provided alongside the original FTS models in Fig. 8. The purpose of this was to determine whether the use of more advanced numerical models provided better estimations of extreme erosion than simpler empirical ones. As has been previously discussed in this paper, the computational times associated with using XBeach in such a framework are not feasible in practical situations. For this reason, the study of Callaghan et al. (2013) modelled a range of individual events using XBeach and determined a database of erosion volumes; unlike the Kreibel and Dean and SBEACH models that were incorporated directly into

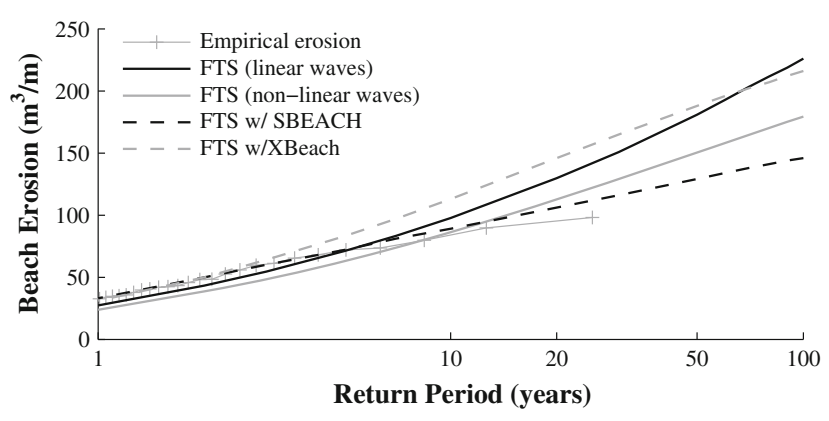

Fig. 8 Return level estimates from modelling with the FTS model of Callaghan et al. (2008) using linear and nonlinear ( Callaghan and Wainwright 2013) wave propagation; and from the SBEACH and XBeach modelling of Callaghan et al. (2013) 
the FTS. Depending on the statistical storm climate generated, this database could then be referenced to determine the associated erosion and allow for extreme predictions to be made. Until significant advancements in the ability to use these type of models for longer term predictions are made, the inclusion of such a model within the statistical framework (i.e. modelling every event) is not considered appropriate due to the extreme computational requirements highlighted by Callaghan et al. (2013).

The results showed that the most realistic estimations were provided by using SBEACH as the structural function. That being said, only the XBeach results exhibits a downward trending concave tail, at the extremes, that correlates to an expected finite limit on erosion volume.

\subsection{Statistical Process-based Approach}

More recently, Pender and Karunarathna (2013) further expanded on the FTS model using XBeach to simulate both erosion and accretion during recovery periods. This method, known as the Statistical Process-based Approach (SPA), showed that, by accounting for the physical processes that govern beach accretion, in the XBeach parameter setup, comparable estimations of the annual variability of Narrabeen Beach could be achieved. The calibration of XBeach for accretion was conducted using an annual time period of wave and profile measurements. This was achieved by modelling storm events and calm periods in succession with different XBeach set ups. Figure 9 shows the results of the volumetric (above MSL) change of the beach between 1981 and 1982 from the best calibrated XBeach model.

However, as the purpose of the study presented by Pender and Karunarathna (2013) was to demonstrate the methodology of the SPA, only a 10-year synthetic storm climate was simulated. To more comprehensively assess the capabilities of the SPA procedure a 100 year storm climate has been simulated here. This simulation should allow for the estimation of up to 10-year return levels. To ensure that the modelling was as computationally efficient as possible; the recovery periods

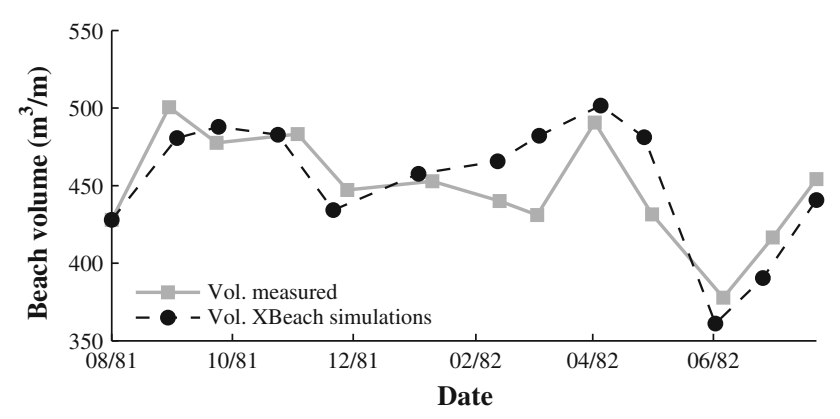

Fig. 9 Calibration of XBeach for modelling annual volumetric variability of Narrabeen Beach between storm events were simulated using a morphological acceleration factor (Pender and Karunarathna 2013) and the entire simulation was implemented using MPI parallel computing.

The results from the SPA model are given in Fig. 10, with the plot being curtailed at the 10 year RP. From these results, it is clear that the SPA consistently overestimates the observed erosion levels. However, it should be noted that, when the results were compared with the measured erosion levels with no correction (Fig. 3), rather than the average, these results are much more comparable (Fig. 10). An extensive discussion on the reasons of this overestimation and the limitations of the SPA approach is given by Pender and Karunarathna (2013) and therefore only a summary is provided here. The main conclusions drawn from the study were that, although the methodology has gone a long way to demonstrate the ability of using XBeach for making longer term statistical predictions, the inherent limitations in the simplified division of wave climate into erosion and accretion periods means that the SPA cannot capture the bar dynamics of Narrabeen Beach effectively. This was highlighted as the main obstacle to overcome, should this type of method become suitable for practical use in the future.

Even after advancement in the modelling methodology in the SPA, it is thought that this approach is not as suitable to extreme erosion estimation as the FTS type models. This is mainly down to the computational time that is required to model long time series of storm induced beach erosion and post storm beach recovery using XBeach. The modelling of 100 years of beach change takes approximately two months. The computational time of fully process-based morphodynamic models has always been one of their main limitations. However, the demonstration of the ability to simulate beach profile change at shorter (annual to decadal) timescales using this type of model has certain advantages over the other approaches. Namely, simulation of antecedent beach profile states which enable the investigation and simulation of variability of various beach properties, such as volume and contour position, to be predicted.

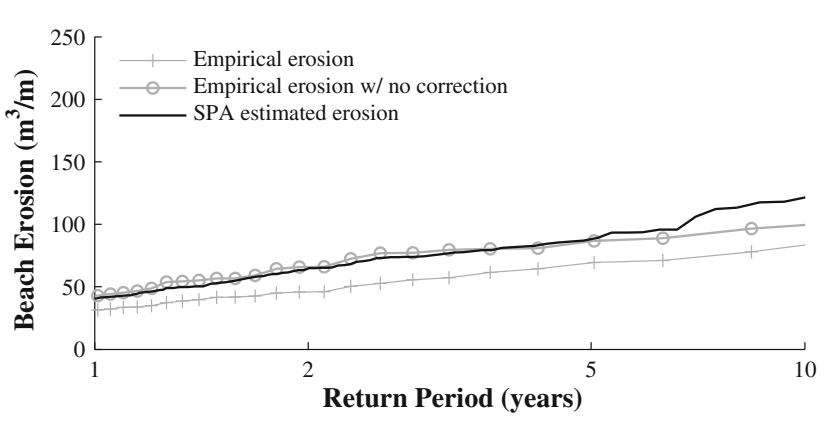

Fig. 10 Return level estimates from modelling 100 years with the SPA method of Pender and Karunarathna (2013) 


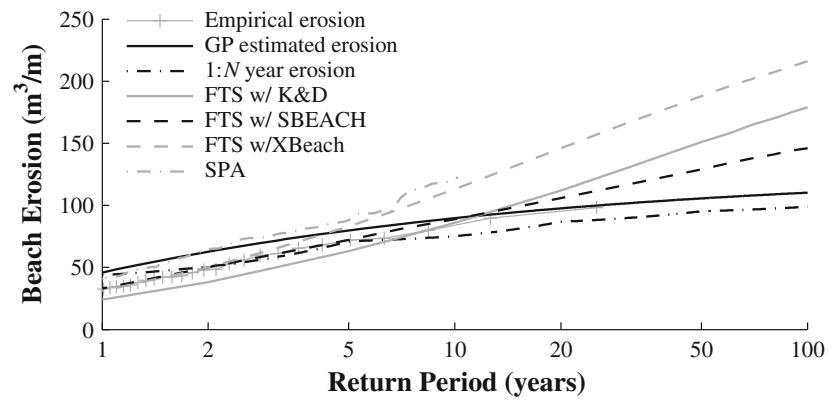

Fig. 11 Comparison of extreme erosion estimation methods

\section{Comparison of methods}

To assess differences, the results for certain methods are compared. Due to the progression of the FTS methodology by Callaghan and Wainwright (2013) only these results using the Kriebel and Dean (1993) model are provided, as they supersede the original Callaghan et al. (2008) results. The comparison is provided in Fig. 11 and uses results from:

(i) GP distribution estimated erosion (more suitable than the GEV distribution)

(ii) $1: N$ year storm event modelling erosion

(iii) FTS estimated erosion with the Kriebel and Dean (1993) erosion model

(iv) FTS estimated erosion with SBEACH erosion model

(v) FTS estimated erosion with XBeach erosion model

(vi) SPA estimated erosion.

Examining the plots in Fig. 11 the differences between the methods become evident, with significant variation at higher RPs. Although the limitations of a 1: $N$ year approach have been well documented, it can be seen from Fig. 11 that this type of method produces comparable estimates with the more complex FTS approach up to a RP of approximately 10 years. Due to the simplicity, and lower empirical data requirements, of a 1:N year approach, these results should not be understated.

Additionally, the simple empirical approach of estimating using a GP distribution produces comparable results up to a
RP of approximately 15 years. Again the limitations of this approach are obvious at higher return periods but, should a suitable empirical erosion data set exist this simple method is suitable for providing a quick estimate of medium-term erosion levels.

What can be taken from this comparison is, depending on the project requirements and data availability, the simple methods may be able to provide adequate estimations of beach erosion. However, due to considerable variation in the methods at the extreme RPs it is the responsibility of the engineer or scientist to understand the limitations of each method and implement them accordingly.

\section{Progression of methodologies}

In terms of the numerical modelling techniques used to quantify erosion, the approach of Pender and Karunarathna (2013) can be considered the most 'up-to-date', as the entire timeseries (erosion and recovery) is modelled using a process based model. However, it was shown that, although the methodology produced encouraging results at an annual to decadal time scale, the simplifications made in determining erosion and accretion periods, and the computational limitations are major factors that need to be addressed to progress such a methodology.

When the original FTS methodology was developed, Callaghan et al. (2008) highlighted the major limitation being the use of the empirical methods to determine erosion and accretion, which led to the progression of techniques discussed previously. With the limitations using a fully processbased model being highlighted, progression of the statistical modelling techniques is an area for potential development. One such technique is that proposed by Corbella and Stretch (2013) who simulated a multivariate storm climate using trivariate copulas. This was achieved using bivariate copulas to allow for dependency between wave height $(H)$ and storm duration $(D)$; and $H$ and wave period $(T)$. Using copulas to model the dependency of $H$ and $T$ allows for the inclusion of the steepness limit associated with individual waves. In addition, their analyses showed that the spacing

Table 1 Estimated storm events used to determine erosion of Narrabeen Beach

\begin{tabular}{|c|c|c|c|c|c|c|c|c|c|c|c|}
\hline \multicolumn{2}{|l|}{1 year RP } & \multicolumn{2}{|l|}{5 year RP } & \multicolumn{2}{|l|}{10 year RP } & \multicolumn{2}{|l|}{20 year RP } & \multicolumn{2}{|l|}{50 year RP } & \multicolumn{2}{|l|}{100 year RP } \\
\hline$H_{\mathrm{s}, \max }(\mathrm{m})$ & $D(\mathrm{~h})$ & $H_{\mathrm{s}, \max }(\mathrm{m})$ & $D(\mathrm{~h})$ & $H_{\mathrm{s}, \max }(\mathrm{m})$ & $D(\mathrm{~h})$ & $H_{\mathrm{S}, \max }(\mathrm{m})$ & $D(\mathrm{~h})$ & $H_{\mathrm{s}, \max }(\mathrm{m})$ & $D(\mathrm{~h})$ & $H_{\mathrm{s}, \max }(\mathrm{m})$ & $D(\mathrm{~h})$ \\
\hline 4.00 & 82 & 4.00 & 127 & 4.00 & 143 & 4.00 & 158 & 4.00 & 176 & 4.00 & 189 \\
\hline 5.35 & 67 & 7.15 & 108 & 8.00 & 125 & 8.90 & 141 & 10.16 & 160 & 11.18 & 173 \\
\hline 5.94 & 35 & 7.96 & 35 & 8.87 & 35 & 9.80 & 35 & 11.17 & 35 & 12.25 & 35 \\
\hline 4.87 & 76 & 6.41 & 119 & 6.41 & 135 & 8.03 & 150 & 9.21 & 169 & 10.17 & 182 \\
\hline 5.68 & 55 & 7.62 & 90 & 7.62 & 106 & 9.44 & 122 & 10.75 & 142 & 11.80 & 156 \\
\hline
\end{tabular}


between events and water level are independent and therefore, they can be simulated using their marginal distributions as in Callaghan et al. (2008). This methodology allowed for the generation of a multivariate $\left(H_{\mathrm{s}, \max }, D\right.$ and $\left.T_{\mathrm{S}}\right)$ storm climate that provided a good visual comparison with the measured data. Although this provides more detailed statistical representation of the dependencies between storm parameters, it still requires the identification of independent storm events in the wave climate.

This identification of storm events to define erosion periods is one of the major limitations in all of the methods discussed in this paper. Although in the case of Narrabeen Beach this can be justified (Harley et al. 2009) this threshold level may not be so clear at other locations.

In their empirical model of shoreline change, Davidson et al. (2013) distinguished between erosion and accretion periods at Narrabeen Beach by using the dimensionless fall velocity (Dean 1973; Gourlay 1968). This accounts for the antecedent state of the beach, a factor shown to control the level of erosion and future state of the beach (Harley et al. 2009). The inclusion of such a mechanism in the current methodologies would allow for the limitation of the ad hoc switching between erosion using a storm threshold to be overcome and potentially make these types of modelling frameworks more applicable to locations that are not so clearly controlled by erosion during storm events.

Although advancement of modelling techniques will help to provide better realisations of the physical processes; it is thought that the next major step is to test methods like the FTS and SPA at different locations. While the methods presented and discussed above have resulted in valuable progression of the tools required for decision making in coastal management projects, for these to become common practice, global applicability is paramount. This sort of global validation will require a vast quantity of measured data (i.e. wave, tide, beach profiles) from a number of field sites for a number of years.

Despite the fact that there may be a number of these sites around the world, the current methodologies, outlined here, can only be effectively applied to beaches where erosion levels are controlled by high-energy wave events and cross-shore sediment transport dominates. That being said, the application of some of these methodologies to different sites is a significant step in the development of these methodologies for management purposes.

\section{Conclusions}

This paper has presented an evaluation of various methodologies available for quantifying extreme beach erosion. It has been shown that, should the site of interest have a regular series of profile measurements that accurately represent erosion (which are relatively rare), the use of extreme value distributions can provide realistic estimations of extreme erosion volumes. However, this method is limited by the requirement for empirical erosion volumes and a complete lack of inclusion of the physical erosion processes during storm events.

The use of numerical models to simulate erosion from a 1:N year benchmark event has been shown to give a reasonable estimation of erosion at lower return periods $(<10$ years) but underestimation of extremes. This confirms the requirement for a representation of the actual storm climate.

The greatest contribution to this field is that of Callaghan et al. (2008) who presented the FTS methodology that combined the multivariate statistical simulation of a storm climate with empirical models of beach erosion and recovery. The development of the FTS modelling framework has led to a number of recent studies attempting to advance this approach by the application of more detailed structural functions to estimate erosion and accretion. In addition to this, Callaghan et al. (2013) assessed the suitability of different erosion functions and used a bootstrapping method to enable convergence at extreme probabilities and allow for the determination of confidence limits of the estimations. This showed that, although the progression of morphodynamic modelling has led to a number of detailed process-based models, use of such models within this type of long-term framework does not have any substantial advantages over simpler empirical and semi-empirical models, apart from the behaviour at the extreme tail.

The logical, if not extremely ambitious, progression of this type of methodology is to have a process-based model capable for simulation of the entire beach profile over the entire time period of interest. However, realistic expectation that such a model will be delivered, and be computationally efficient enough for this type of task, in the near future is unlikely. The SPA methodology presented by Pender and Karunarathna (2013) can be considered as an initial step in this direction. Unlike the other techniques presented and discussed, the SPA does allow for the modelling of the entire beach face, thus having the flexibility to determine the variation in other quantities (e.g. beach volume, contour position and profile envelope) and also the ability to determine variability of beach states rather than solely focusing on quantifying erosion volumes. However, the computational time alone for such a methodology renders it impractical for use in simulations longer than a decadal scale.

As the advancements in the techniques using more detailed numerical models have been shown to, not increase in the accuracy of erosion estimates, and have a detrimental effect on the simulations, the progression of such type of methodology is uncertain. Although the use of the statistical model of Corbella and Stretch (2013) has been highlighted as a potential advancement, this approach still requires the limitation of the division of the wave climate into storm (erosion) events. 
As previously mentioned, although this may be considered suitable for Narrabeen Beach, this division may not be as clear at other locations.

Until this happens, from this study, and that of Callaghan et al. (2013), conducted at Narrabeen Beach, the FTS model of Callaghan et al. (2008), with the detailed wave propagation of Callaghan and Wainwright (2013), can be considered the most practical tool available at making robust and accurate estimates of storm-induced extreme beach erosion.

Although the methods presented here have shown good correlation with the empirical data, it should be emphasised that these methods have only been tested at one location. Should future coastal management projects begin to make use of such methodologies a comprehensive global calibration is required. This is considered as the most important advancement, should these types of frameworks become useable for decision making in the near future.

Acknowledgments The authors would like to thank the Engineering and Physical Sciences Research Council (EPSRC) for funding the $\mathrm{PhD}$ research of Douglas Pender. Also, Douglas Pender and Harshinie Karunarathna acknowledge the EPSRC funded Flood MEMORY project (EP/K013513/1). Prof. Andrew Short (University of NSW) and Assc. Prof. Rosh Ranasinghe (UNESCO-IHE) are greatly appreciated for providing the Narrabeen Beach data; Dr. Jaap van Thiel de Vries (Deltares), Mr. Bas Hoonhout (Deltares), and Mr. Robert McCall (Plymouth University) for their discussions regarding the XBeach modelling; Dr. Mitchell Harley (University of Ferrara) for the use of Fig. 1. Finally, the authors are thankful to the reviewers, whose constructive comments helped improve the original manuscript.

\section{References}

Bolle A, Mercelis P, Roelvink D, et al. (2010) Application and Validation of XBeach for Three Different Field Sites. Proc. 32nd Int. Conf. Coast. Eng.

Bruun P (1962) Sea-level rise as a cause of shore erosion. J Waterw Harbours Div ASCE 88:117-130

Callaghan DP, Wainwright D (2013) The impact of various methods of wave transfers from deep water to nearshore when determining extreme beach erosion. Coast Eng 74:50-58

Callaghan D, Nielsen P, Short A, Ranasinghe R (2008) Statistical simulation of wave climate and extreme beach erosion. Coast Eng 55:375390. doi:10.1016/j.coastaleng.2007.12.003

Callaghan D, Ranasinghe R, Short, (2009) Quantifying the storm erosion hazard for coastal planning. Coast Eng 56:90-93. doi:10.1016/ j.coastaleng.2008.10.003

Callaghan DP, Ranasinghe R, Roelvink D (2013) Probabalistic estimation of storm erosion using analytical, semi-empirical, and process based storm erosion models. Coast Eng 82:64-75. doi:10.1016/j. coastaleng.2013.08.007

Church J, White NJ (2006) A 20th century acceleration in global sealevel rise. Geophys Res Lett. doi:10.1029/2005GL02482

Coles S (2001) An Introduction to Statistical Modelling of Extreme Values, 1st Editio. Springer.

Cooper JAG, Pilkey OH (2004) Sea-level rise and shoreline retreat: time to abandon the Bruun Rule. Glob Planet Change 43:157-171. doi:10. 1016/j.gloplacha.2004.07.001
Corbella S, Stretch DD (2013) Simulating a multivariate sea storm using Archimedean copulas. Coast Eng 76:68-78. doi:10.1016/j. coastaleng.2013.01.011

Davidson MA, Splinter KD, Turner IL (2013) A simple equilibrium model for predicting shoreline change. Coast Eng 73:191-202. doi:10.1016/j.coastaleng.2012.11.002

De Alegria-Arzaburu AR, Williams JJ, Masselink G (2010) Application of XBeach to Model Storm Response on a Macrotidal Gravel Barrier. Proc. 32nd Int. Conf. Coast. Eng.

Dean RG (1973) Heuristic Models of Sand Transport in the Surf Zone. First Aust. Conf. Coast. Eng. (1973) Eng . Dyn, Coast, Zo

Dissanayake DMPK, Ranasinghe R, Roelvink JA (2009) Effect of Sea Level Rise in Tidal Inlet Evolution: a Numerical Modelling Approach. In: Proceedings of the 10th International Coastal Symposium, pp 942-946.

Ferreira JA, Soares CG (2000) Modelling distributions of significant wave height. Coast Eng 40:361-374. doi:10.1016/ S0378-3839(00)00018-1

Gourlay MR (1968) Beach and Dune Erosion. Delf Hydraulics Laboratory, Report M935/M936.

Harley MD, Turner IL, Short A, Ranasinghe R (2009) An empirical model of beach response to storms - SE Australia. Proc. 19th Australas. Conf. Coast. Ocean Eng.

Harley MD, Turner IL, Short AD, Ranasinghe R (2010) Interannual variability and controls of the Sydney wave climate. Int J Climatol 30:1322-1335. doi:10.1002/joc.1962

Harley MD, Turner IL, Short AD, Ranasinghe R (2011a) A reevaluation of coastal embayment rotation: The dominance of crossshore versus alongshore sediment transport processes, CollaroyNarrabeen Beach, southeast Australia. J Geophys Res. doi:10.1029/ 2011JF001989

Harley MD, Turner IL, Short AD, Ranasinghe R (2011b) Assessment and integration of conventional, RTK-GPS and image-derived beach survey methods for daily to decadal coastal monitoring. Coast Eng 58:194-205. doi:10.1016/j.coastaleng.2010.09.006

Hawkes PJ, Gouldby BP, Tawn JA, Owen MW (2002) The joint probability of waves and water levels in coastal engineering design. $\mathbf{J}$ Hydraul Res 40:241-251

Hoffman J, Hibbert K (1987) Public Works Department, Coastal Branch, N.S.W., PWD. Report 87040:157

Karunarathna H, Pender D, Ranasinghe R et al (2014) The effects of storm clustering on beach profile variability. Mar Geol 348:103-112. doi:10.1016/j.margeo.2013.12.007

Kriebel DL, Dean RG (1993) Convolution Method for Time-Dependent Beach-Profile Response. J Waterw Port, Coast Ocean Eng 119:204226

Kulmar M, Lord D, Sanderson B (2005) Future Directions for Wave Data Collection in New South Wales. Proc. Coasts Ports Coast. Living - Living Coast; Australas, Conf

Larson M, Kraus N (1989) SBEACH: numerical model for simulating storm induced beach change. Report 1, Empirical Foundation and Model Development, Tech Rept. 267.

Lindemer CA, Plant NG, Puleo Ja et al (2010) Numerical simulation of a low-lying barrier island's morphological response to Hurricane Katrina. Coast Eng 57:985-995. doi:10.1016/j.coastaleng.2010.06. 004

Lord D, Kulmar M (2000) The 1974 Storms Revisited: 25 Years Experience in Ocean Wave Measurement Along the South-East Australian Coast. Proc. 27th Int. Conf. Coast. Eng. Sydney, Australia, pp 559572.

McCall RT, Van Thiel de Vries JSM, Plant NG et al (2010) Twodimensional time dependent hurricane overwash and erosion modeling at Santa Rosa Island. Coast Eng 57:668-683. doi:10.1016/j. coastaleng.2010.02.006 
Pender D, Karunarathna H (2013) A statistical-process based approach for modelling beach profile variability. Coast Eng 81:19-29. doi:10. 1016/j.coastaleng.2013.06.006

Ranasinghe R, McLoughlin R, Short A, Symonds G (2004) The Southern Oscillation Index, wave climate, and beach rotation. Mar Geol 204:273-287. doi:10.1016/S0025-3227(04)00002-7

Ranasinghe R, Callaghan D, Stive MJF (2011) Estimating coastal recession due to sea level rise: beyond the Bruun rule. Clim Change 110:561-574. doi:10.1007/s10584-011-0107-8

Reeve DE, Karunarathna H (2009) On the prediction of long-term morphodynamic response of estuarine systems to sea level rise and human interference. Cont Shelf Res 29:938-950. doi:10.1016/j.csr. 2009.01.010

Roelvink JA, Reniers A, van Dongeren A et al (2009) Modelling storm impacts on beaches, dunes and barrier islands. Coast Eng 56:11331152. doi:10.1016/j.coastaleng.2009.08.006

Roelvink JA, Reniers A, van Dongeren A et al (2010) XBeach Model Description and Manual. All.

Short AD (1984) Beaches and Nearshore Facies: Southeast Australia. Mar Geol 60:261-282

Short AD (2006) Australian Beach Systems-Nature and Distribution. J Coast Res 221:11-27. doi:10.2112/05A-0002.1

Short AD, Trenaman NL (1992) Wave climate of the Sydney region, an energetic and highly variable ocean wave regime. Aust J Mar Freshw Res 43:765. doi:10.1071/MF9920765

Short A, Trembanis A (2004) Decadal scale patterns in beach oscillation and rotation Narrabeen beach, Australia: time series, PCA and wavelet analysis. J Coast Res 20:523-532
Small C, Nicholls RJ (2003) A Global Analysis of Human Settlement in Coastal Zones. J Coast Res 19:584-599

Splinter KD, Holman RA, Plant NG (2011) A behavior-oriented dynamic model for sandbar migration and 2DH evolution. J Geophys Res 116:1-21. doi:10.1029/2010JC006382

Stive MJF, Ranasinghe R, Cowell PJ (2009) Sea level rise and coastal erosion. Handb. Coast. Ocean Eng. World Scientific, pp 1023-1038.

Tawn JA (1988) An extreme-value theory model for dependent observations. J Hydrol 101:227-250

Thompson P, Cai Y, Reeve D, Stander J (2009) Automated threshold selection methods for extreme wave analysis. Coast Eng 56:10131021. doi:10.1016/j.coastaleng.2009.06.003

Van Rijn LC, Walstra DJR, Grasmeijer B et al (2003) The predictability of cross-shore bed evolution of sandy beaches at the time scale of storms and seasons using process-based Profile models. Coast Eng 47:295-327

Williams JJ, de Alegría-Arzaburu AR, McCall RT, van Dongeren A (2012) Modelling gravel barrier profile response to combined waves and tides using XBeach? Laboratory and field results. Coast Eng 63:62-80. doi:10.1016/j.coastaleng.2011.12.010

Wright LD, Short AD (1984) Morphodynamic Variability of Surf Zones and Beaches: A Synthesis. Mar Geol 56:93-118 